\title{
While climbing the hill, you think it's possible
}

\author{
Paolo Martelletti
}

Published online: 11 August 2009

(C) Springer-Verlag 2009

\section{Amat victoria curam $^{1}$}

My dear readers, for 5 years we have followed the evolution of this journal. Since late spring 2004, after my appointment as Editor-in-Chief, together we have endured many things and accomplished even more. It has been both an honour and a privilege for me as a scientist to accept this challenge. Today I know that all my efforts have not been vain.

At first, I intended not to write anything until the fateful date of June 2011, which is when I thought I could finally share with you, after an anxious wait, JHP's long-yearned evaluation in terms of the impact factor (IF) [1, 2]. However, fate decided to change my plans again, as happened in 2006 with the unexpectedly early inclusion of The Journal of Headache and Pain (JHP) in PubMed/Medline.

Indeed, ISI Thompson Reuters included JHP in Journal Citation Reports (JCR) 2 years beforehand. The entry rank of 1.875 is absolutely respectable in light of JHP's young age. The fact that inclusion occurred in two subject categories at the same time, namely Neurosciences and Clinical Neurology, is particularly remarkable. If a crude analysis in terms of numbers (IF) puts JHP in last position among the three international headache journals, a quantitative evaluation taking into account inclusion in more sectors locates JHP in second place.

Electronic supplementary material The online version of this article (doi:10.1007/s10194-009-0145-z) contains supplementary material, which is available to authorized users.

P. Martelletti $(\square)$

Department of Clinical and Molecular Sciences,

2nd School of Medicine, Sant'Andrea Hospital,

Sapienza University of Rome, Via di Grottarossa 1035,

00185 Rome, Italy

e-mail: paolo.martelletti@uniroma1.it
An exhaustive report of JCR data is available online as Electronic supplementary material, for those who wish to go into more detail.

I have already expressed my deep gratitude to the members of the Editorial Board, from the Co-editor to the Managing Editor, as well as to the Advisory Board, to EHF's Board of Directors and to Springer, since I believe this was the outcome of elaborate teamwork: the Editors shared with me the decision processes, while the EHF provided the platform where we could take root. Springer managed the production process with its usual superlative professionalism and the unconditional support I received allowed me to exert an appropriate degree of cultural independence from my first day in charge.

However, the most heartfelt thanks go to those who believed in JHP and contributed to its growth through manuscript submission, punctual reviewing activity and, most importantly, the citation of JHP articles which made the rating in JCR possible. Without their precious help, climbing the hill would have been of no use in terms of results, no matter how much perseverance and abnegation I had invested. Therefore, an all-embracing "thank you" goes to everybody.

I also wish to thank those who showed their interest towards JHP with fair play, as well as those who did not take up JHP's cause straightaway. Both attitudes strengthened my belief in having made the right choice.

On the other hand, I know well that from now on things could get harder. Being aware of a great success could lead one to rest on one's laurels, and therefore provide new nourishment for ancient scepticism. As long as the actors on this creative stage keep believing in this project, we will

\footnotetext{
${ }^{1}$ Victory favours those who take pains

Caius Valerius Catullus, 87-54 BC, Carmen LXII.
} 
be able to confirm our scientific position and point towards new clinical research areas in headache. In this way, our contribution to keeping headache disorders out of the shadows will be significant.

Only today the future of JHP appears clear to me. I am certain it will survive to our passion and enthusiasm. JHP, now you can dance the haka.

\section{References}

1. Martelletti P (2008) A tier-upon-tier march towards the impact factor. J Headache Pain 9:197-198

2. Martelletti P (2009) New policies to consolidate the journals's hold in its latest position. J Headache Pain 10:1-2 